Vol. 2, No. 2, Desember 2017, pISSN 2527-2853, eISSN 2549-2985

\title{
Perancangan Mebel Kantor Kezia Karin Surabaya Berdasarkan Ilmu Ergonomi
}

\author{
Grace Safenla1, Felycia Agustin ${ }^{2}$, Windy Novelin ${ }^{3}$ \\ 1,2,3 Program Studi Desain Interior, Universitas Kristen Petra \\ J1. Siwalankerto petra 121-131, Surabaya \\ ${ }^{1}$ gracesafenla@gmail.com, ${ }^{2}$ felyciaagustin15@gmail.com, ${ }^{3}$ windy.novelin@gmail.com
}

\begin{abstract}
ABSTRAK
Aspek sosial, psikologi dan fisik di lingkungan kerja memainkan peran besar dalam mempengaruhi produktivitas kerja seseorang. Lingkungan kerja yang kondusif memberi rasa aman dan mengajak pegawai untuk bekerja secara optimal. Salah satu usaha untuk menciptakan suasana yang menjamin kerja optimal ini membutuhkan furniture yang mempermudah aktivitas penggunanya. Desain mebel yang efektif tidak hanya mampu mencukup kebutuhan kerja tetapi juga sanggup untuk menghemat ruang kerja dan gerak sambil menyediakan keamanan dan kenyamanan bagi pengguna untuk jangka waktu yang panjang. Desain furniture multifungsi yang mengikuti standar ergonomi meningkatkan persentasi efisiensi dan ketepatan waktu.
\end{abstract}

Kata kunci: Lingkungan kerja; desain furniture; standart ergonomi

\section{ABSTRACT}

The social, psychological and physical aspects in the workplace play a major role in influencing one's productivity. A conducive working environment provides a sense of security and engages employees to work optimally. In an effort to create the atmosphere that ensures optimal work, a workplace needs furniture design is not only adequate in assisting the work effort but also capable in minimizing work space and motion while providing security and comfort for users for a long period of time. Multifunctional furniture design that follow the strandard ergonomics improves the efficiency and timeliness percentage.

Keywords: Workplace; furniture design; standard ergonomics

\section{PENDAHULUAN}

Dalam setiap lingkaran kehidupan, semua individu akan melewati tahap di mana mereka harus menjadi mandiri secara finansial. Adalah sebuah kewajiban setiap orang dewasa untuk belajar menghidupi diri sendiri dengan bekerja. Tidak hanya untuk menghidupi kebutuhan premier namun kebutuhan sekunder dan tersier pum juga penting untuk keberlangsungan hidup. Terdapat banyak sekali lapangan pekerjaan yang ada, salah satunya adalah pekerja kantoran.

Seorang pekerja kantoran menghabiskan waktu sekitar delapan sampai sepuluh jam sehari di lingkungan kerja. Lingkungan kerja adalah segala sesuatu yang ada disekitar para pekerja yang dapat mempengaruhi kepuasan kerja karyawan dalam melaksanakan pekerjaannya sehingga hasil kerja yang maksimal dapat diperoleh. Dalam lingkungan kerja yang suportif terdapat fasilitas kerja yang mendukung karyawan dalam penyelesaian tugas secara efisien guna meningkatkan produktivitas dan kepuasan para karyawan.

Menurut (Sedarmayanti dalam Wulan, 2011:21) menyatakan bahwa secara garis besar, jenis lingkungan kerja terbagi menjadi dua faktor yaitu faktor lingkungan kerja fisik dan faktor lingkungan non fisik. Faktor lingkungan kerja fisik termasuk: pewarnaan, penerangan, udara, suara bising, ruang gerak, keamanan, dan kebersihan. Faktor lingkungan kerja non fisik termasuk: struktur kerja, tanggung jawab kerja, perhatian dan dukungan pemimpin, kerja sama antar kelompok, dan kelancaran komunikasi. 
Untuk mencapai produktivitas maksimal, lingkungan kerja harus memiliki hubungan harmonis dengan kebutuhan manusia. Abraham Maslow menyusun teori motivasi manusia, di mana variasi kebutuhan manusia dipandang tersusun dalam bentuk hirarki atau berjenjang. Terdapat 5 hirarki kebutuhan Maslow yang direpresentasikan dalam bentuk piramida dengan kebutuhan yang lebih mendasar ada dibagian paling bawah. Kebutuhan manusia adalah sebagai berikut: kebutuhan fisiologi, keamanan, dimiliki dan dicintai, harga diri, dan aktualisasi diri. Dari kelima kebutuhan manusia ini, kebutuhan fisiologis dan keamanan sangat berhubungan dekat dengan perancangan desain lingkungan kerja. Contoh kebutuhan fisiologis adalah kebutuhan airconditioning (AC) pada cuaca panas untuk menghindari perasaan gerah, keringat berlebihan, atau sakit kepala. Semua efek negatif dari cuaca panas ini dapat mengganggu kenyamanan dan konsentrasi pekerja. Kebutuhan fisiologis lainnya termasuk perwarnaan yang tidak memberi efek silau atau cahaya yang terlalu terang atau redup yang mengganggu penglihatan, ruangan yang terlalu bising sehingga merusak konsentrasi kerja, dan sebagainya. Keamanan di lingkungan kerja mencakup keamanan dalam menggunakan furniture atau fasilitas-fasilitas lain kantor misalnya semua sistem kabel listrik, telepon, internet, harus ditutup dan diatur sedemikian rupa agar tidak terjuntai ke lantai. Contoh lain keamanan adalah pembuatan sudut-sudut meja yang tumpul sehingga tidak melukai pekerjanya.

Aktivitas rutin pekerja kantoran tidak lepas dari penggunaan funiture dalam jangka waktu yang lama. Salah satu pekerjaan yang furniture-nya perlu diberikan lebih banyak perhatian adalah furniture yang digunakan oleh pekerja-pekerja desain interior. Jam kerja desainer kurang lebih delapan jam sampai sepuluh jam perhari namun hanya kebutuhan bekerja saja yang dapat difasilitasi oleh furniture kantor. Berdasarkan data lapangan yang ada, PT. Pelindo III, Sub-Co, dan Kezia Karin Interior Desain, menggunakan mebel-mebel biasa yang ada dipasaran, dan desain mebel tersebut hanya mendukung aktivitas kerja saja.

Sebagai seorang desainer, kebutuhan yang bisa dipenuhi adalah kebutuhan fisiologi dan kebutuhan keamanan yang meliputi lingkungan kerja fisik. Dengan semakin mendalamnya pengertian tentang hubungan antara kebutuhan manusia, lingkungan kerja, dan produktivitas maka didirikanlah studi ergonomi.

Studi ergonomi adalah ilmu yang menemukan dan mengumpulkan informasi tentang tingkah laku, kemampuan, keterbatasan, dan karakteristik manusia untuk perancangan mesin, peralatan, sistem kerja, dan lingkungan yang produktif, aman, nyaman dan efektif bagi manusia. Ergonomi merupakan suatu cabang ilmu yang sistematis untuk memanfaatkan informasi mengenai sifat manusia, kemampuan manusia dan keterbatasannya untuk merancang suatu sistem kerja yang baik agar tujuan dapaat dicapai dengan efektif, aman dan nyaman. Ergonomi dibagi menjadi 5 macam studi:

1. Ergonomi fisik: berhubungan dengan antropometri, lingkungan fisik dan biomekanik

2. Ergonomi kognitif: membahas tentang hubungan display dan control. Topik relevan dalam ergonomi kognitif antara lain; beban kerja, pengambilan keputusan dan stress kerja

3. Ergonomi lingkungan: berkaitan dengan pencahayaan, udara dan ruang.

4. Ergonomi organisasi: mengenai komunikasi di dalam lingkungan, organisasi yang membuat perasaan nyaman dalam bekerja.

5. Psikologi terapan: hasil studi psikologi eksperimen dalam desain diperlukan untuk mengetahui kebutuhan dimensi/ukuran tubuh manusia (misalnya, kebiasaan, perilaku dan budaya manusia duduk, berdiri, mengambil sesuatu dan bergerak)

Kebutuhan furniture ergonomi saat beraktivitas menjadi prioritas di lingkungan kerja, di mana tanpa mengaplikasikan ilmu ergonomi, penggunaan furniture dalam jangka panjang akan mengakibatkan efek yang negatif terhadap kesehatan fisik, mental, psikologis, dan sosial. 
Lingkungan kerja yang memenuhi standar ergonomi dapat membantu meningkatkan efisiensi dan ketepatan waktu para pekerja juga menjamin keamanan dan kenyamanan pekerja.

\section{METODE PENELITIAN}

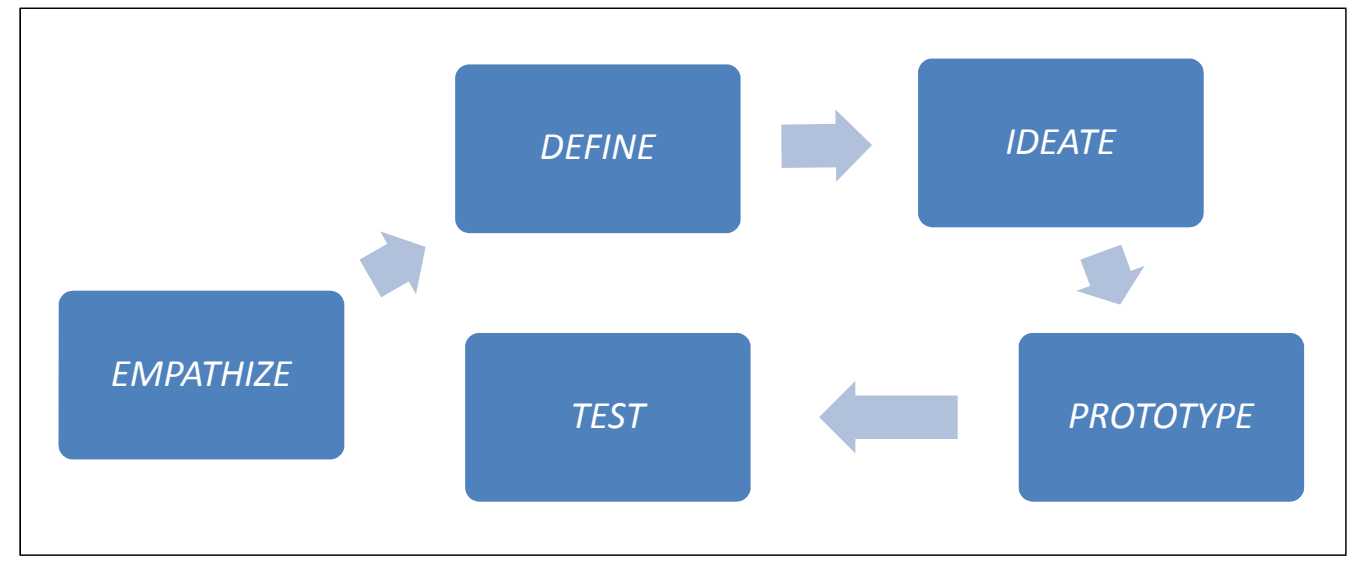

Gambar 1. Bagan Metode Perancangan

Sumber: Metode Penulis (2017)

\section{A. Tahapan Perancangan}

1. Tahap Awal Desain (Empathize)

Empathize merupakan proses awal dalam tahap mendesain. Mencari data - data literatur, data lapangan fisik dan non fisik (data pengguna, aktivitas pengguna, kebutuhan ruang, data tipologi pembanding Pelindo III, Sub Co, Kezia Karin; observasi lapangan, wawancara dengan karyawan/pemilik

\section{Tahap Analisis (Define)}

Selanjutnya masuk dalam tahap pencarian dan pemahaman masalah. Dalam tahap ini dilakukan proses penyususan data - data yang telah dikumpulkan dalam tahap pertama Empathize, kemudian dilanjutkan dengan analisis terhadap data - data tersebut, sehingga nantinya akan ditemukan beberapa masalah yang akan diangkat dibawa ke tahapan selanjutnya. Perancang akan memahami situasi dan kondisi dari proyek perancangan, termasuk memahami permasalahan yang terjadi dan harapan yang diinginkan kedepannya.

\section{Tahap Pencarian Ide (Ideate)}

Dalam tahap ketiga, perancang mulai melakukan penyusunan konsep desain yang dikaitkan dengan permasalahan yang telah dianalisis oleh perancang. Lalu perancang akan membuat konsep yang sekiranya mampu melandasi permasalahan desain, maka dilanjutkan dengan pengeluaran ide - ide desain dalam bentuk skematik dengan beberapa desain alternatif. Hasil dari desain alternatif akan dilakukan evaluasi agar ditemukan kelebihan dan kekurangan dari masing - masing desain. Dari semua alternatif desain dipilih satu terbaik yang paling menjawab kebutuhan desain lalu disempurnakan kembali agar mendapat desain akhir.

\section{Tahap Pembuatan Prototype (Prototype)}

Setelah didapat desain akhir dari semua alternatif yang ada dan telah melakukan pemilihan terhadap alternatif desain yang paling mungkin untuk dijadikan prototype dalam kurun waktu tertentu, maka perancang segera memasukkan gambar kerja ke bengkel yang telah dipilih. 
Biasanya perancang juga diminta untuk membuat maket dengan skala tertentu dengan bahan yang menyerupai bahan asli. Pada saat perancang sudah memasukkan gambar kerja ke bengkel pilihan, maka akan diberi masukan - masukan terkait dengan proses teknis pembuatan oleh tukang, maka perancang akan merevisi gambar kerja untuk yang terakhir kalinya. Setelah direvisi untuk terakhir kalinya, gambar kerja revisi kembali diserahkan kepada tukang untuk pengerjaan prototype. Selama perancangan diharapkan perancang tetap melakukan kontrol pekerjaan tukang, sehingga tidak terjadi kesalahpahaman.

\section{Tahap Evaluasi Uji Coba (Tes)}

Tahap akhir dalam sebuah perancangan adalah ketika prototype 1:1 yang selesai dibuat, kemudian di evaluasi melalui uji coba fungsi, yang ada dalam hal ini dilakukan ada saat evaluasi akhir dan pada saat pameran desain produk di Ciputra World.

\section{HASIL PENELITIAN DAN PEMBAHASAN}

\section{A. Konsep Desain}

Konsep desain mebel berdasarkan fungsi dan kenyamanan akan diterapkan pada meja kerja. Fungsi dan kenyamanan inilah yang menjadi patokan utama dalam mendesain meja kerja ini, yang letak permasalahannya memang pada meja kantor yang sudah ada. Meja yang sudah tersedia hanya mendukung aktivitas kerja dan sisi fungsi dan kenyamanan masih kurang.

\section{Konsep Warna}

Warna yang diambil dominan warna cokelat karena berkarakter elegan dan memiliki stabilitas yang tinggi. Selain itu warna cokelat ini sangat disarankan terutama untuk ruangan yang membutuhakn konsentrasi tinggi seperti ruang belajar (sekolah) atau ruang kerja (kantor). Warna yang digunakan lainnya yaitu warna merah, untuk membuat suasana ruang kerja lebih hidup, dan lebih semangat.

\section{Konsep Bentuk}

Bentukan yang diaplikasikan pada mebel ini bentuk geometri seperti pada umumnya, luasanya juga cukup untuk aktivitas selain kerja. Disertai dengan ruang penyimpanan untuk contoh material-material. Model mejanya tidak akan berubah, hanya saja ada bagian yang bisa diangkat, memberikan ketinggian pada meja untuk aktivitas menggambar. Pada umumnya aktivitas kerja dengan laptop atau komputer kondisi bidang meja jarang bisa mencukupi aktivitas gambar apalagi untuk pekerja interior.

\section{Material}

Material yang jadi bahan utama mebel ini adalah multiplek. Multiplek mudah didapatkan, dan harga terjangkau lalu difinishing dengan duco agar lebih rapi. Kaki meja menggunakan bahan stainless.

\section{B. Alternatif Desain}

\section{Alternatif desain 1}

Meja untuk satu pengguna. Pada bagian kanan meja, ada tempat CPU komputer, ada tempat untuk menaruh alat tulis, bisa juga untuk taruh handphone. Pada sudut meja kiri dijadikan tempat untuk menaruh contoh material yang terserdia. 


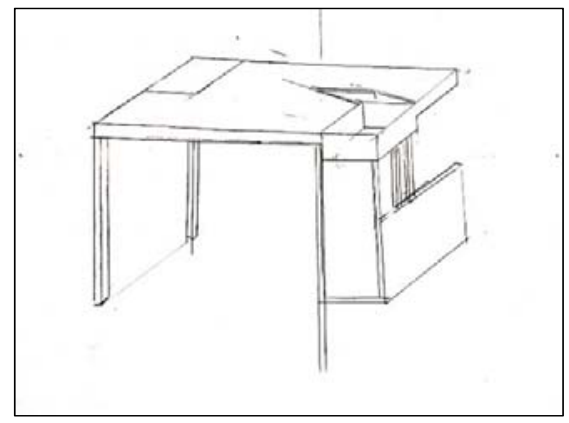

Gambar 2. Alternatif desain 1 Sumber: Dokumentasi Penulis (2017)

\section{Alternatif desain 2}

Meja untuk dua pengguna. Posisi meja memanjang, sisi yang sebelah kiri panjang diberikan tempat untuk menaruh CPU. Diberi pembatas pada area kaki meja. Kondisi bidang rata tidak ada leveling.

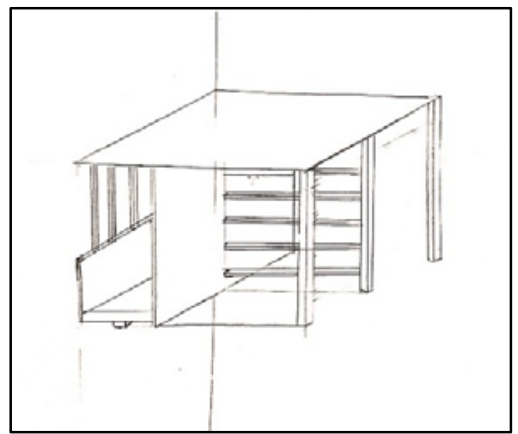

Gambar 3. Alternatif desain 2 Sumber: Dokumentasi Penulis (2017)

\section{$\underline{\text { Alternatif desain } 3}$}

Meja untuk satu pengguna. Pada bagian kiri bawah meja dibuat tempat untuk meletakkan CPU. Dibagian atas ada bagian yang bisa diangkat untuk dijadikan bidang gambar. Lalu ada tempat untuk colokan listrik.

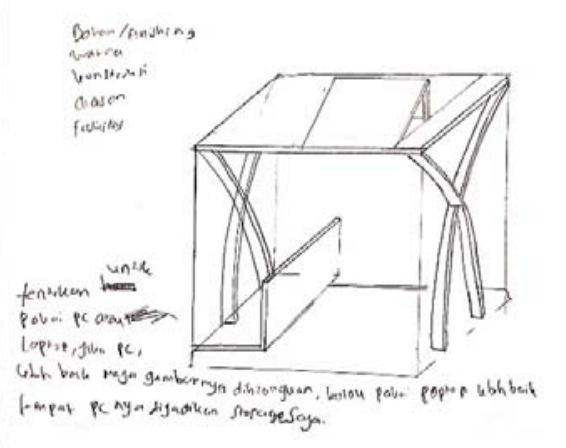

Gambar 4. Alternatif desain 3

Sumber: Dokumentasi Penulis (2017) 
Grace Safenla, Felycia Agustin, Windy Novelin

Perancangan Mebel Kantor Kezia Karin Surabaya Berdasarkan Ilmu Ergonomi

\section{Desain final}

Meja untuk satu orang pengguna. Kondisi meja bisa dijadikan bidang untuk pekerjaan dengan laptop dan juga PC hanya saja tidak ada tempat untuk menaruh CPU. Bagian tengah ada tempat untuk meletakkan keyboard yang tingginya sesuai dengan lekukan tangan. Bagian ini juga dapat dimiringkan, sehingga pekerja bisa menggambar.

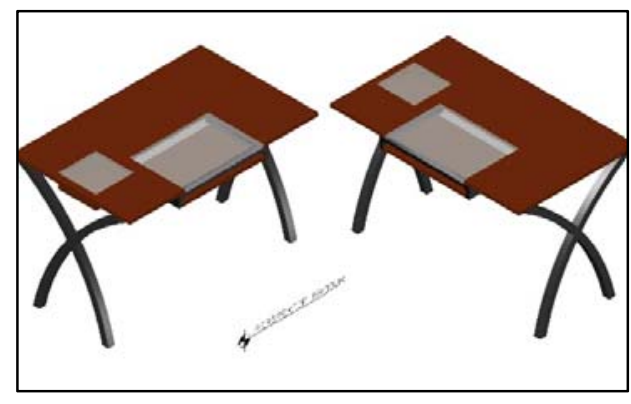

Gambar 5. Perspektif Desain Akhir Sumber: Dokumentasi Penulis (2017)

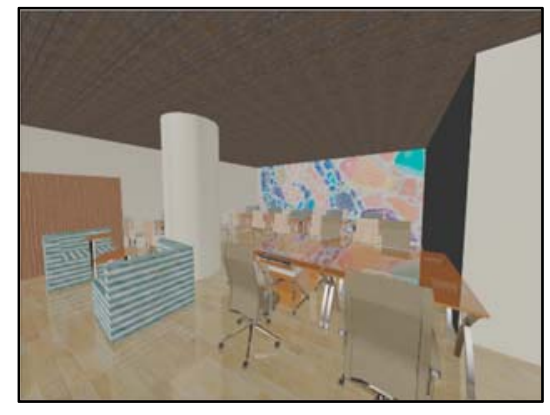

Gambar 6. Perspektif dalam ruang Sumber: Dokumentasi Penulis (2017)

\section{Proses Pembuatan Prototype}

Berikut dilampirkan dokumentasi proses pembuatan mebel:

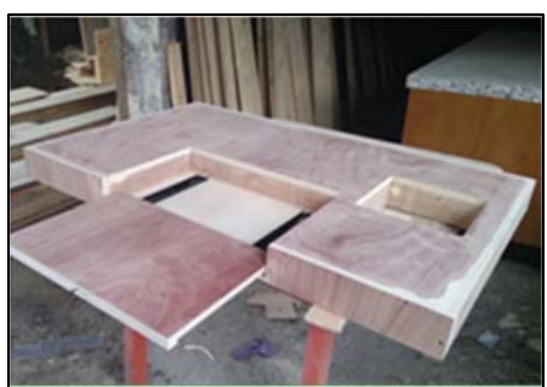

Gambar 7. Rangka bidang alas meja Sumber: Dokumentasi Penulis (2017)

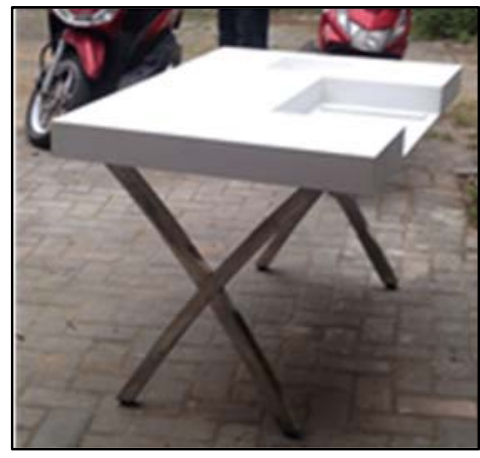

Gambar 9. Meja dalam tahap pengecatan Sumber: Dokumentasi Penulis (2017)

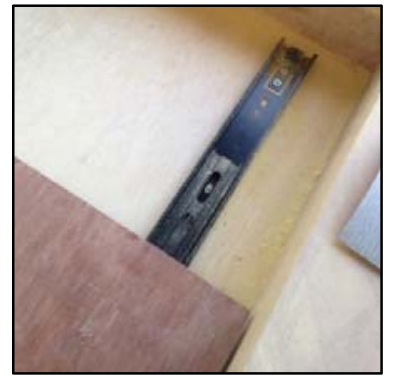

Gambar 8. Sambungan untuk tarikan alas keyboard Sumber: Dokumentasi Penulis (2017)

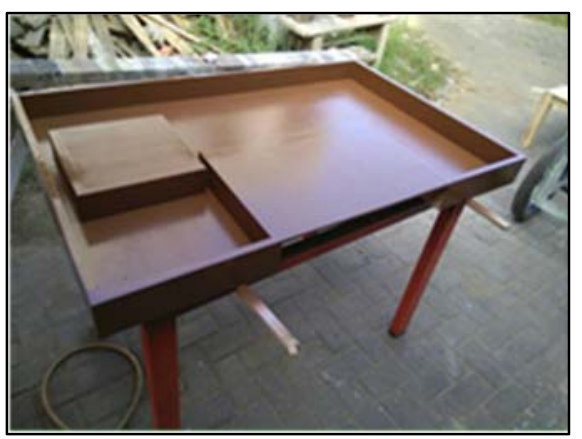

Gambar 10. Alas meja dicat coklat, Finishing duco Sumber: Dokumentasi Penulis (2017) 


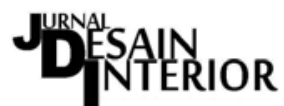

Vol. 2, No. 2, Desember 2017, pISSN 2527-2853, eISSN 2549-2985

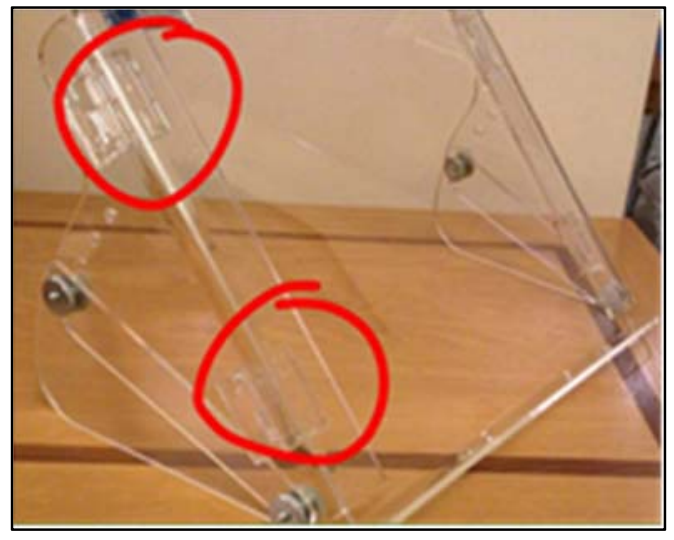

Gambar 11. Alas untuk menggambar Sumber: Dokumentasi Penulis (2017)

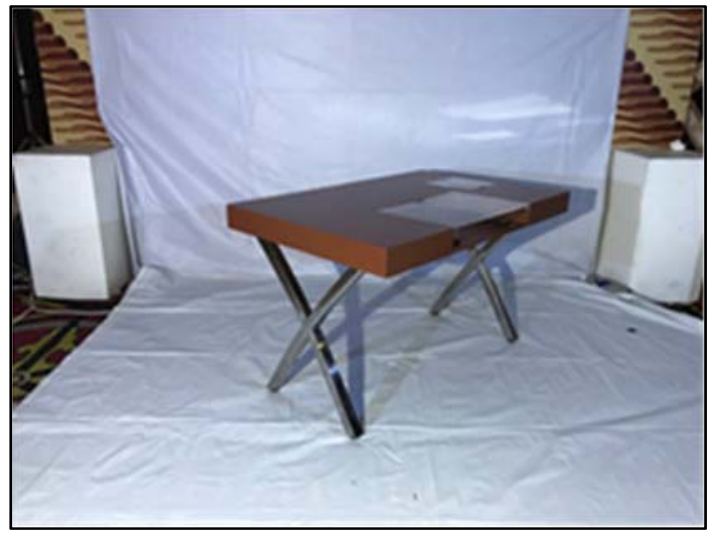

Gambar 12. Meja sudah jadi, Sumber: Dokumentasi Penulis (2017)

\section{E. Definisi Dan Pengertian Kantor}

Pengertian kantor dalam arti "tempat" atau ruangan dan kantor dalam arti "proses" seperti di atas, kantor juga sering diartikan sebagai sarana pemusatan kegiatan-kegiatan yang bersifat administrative atau tepatnya kegiatan-kegiatan yang bersifat manajerial dan fasilitatif. Sebagai contoh, banyak perusahaan-perusahaan besar yang kegiatan proses produksinya berlangsung di suatu daerah, tetapi kantornya utamanya bisa berada di Jakarta atau di tempat yang berbeda. Atau perusahaan-perusahaan multinasional yang memiliki cabang di beberapa Negara, tetapi kantor pusatnya hanya berada di satu Negara.

Dapat ditarik kesimpulan bahwa kantor dalam arti dinamis adalah tempat diselenggarakannya kegiatan tata usaha di mana terdapat ketergantungan sistem antara orang, teknologi, dan prosedur untuk menangani data dan informasi mulai dari menerima, mengumpulkan, mengolah, menyimpan, sampai menyalurkannya.

\section{F. Peralatan dan Furniture Kantor}

Dalam penataan sebuah ruangan kantor tidak lepas dari penyusunan peralatan dan furniture kantor bagi pegawai yang bekerja di suatu perusahaan. Penyusunan peralatan dan furniture yang tepat akan memudahkan pegawai dalam berkomunikasi ataupun dalam proses pelaksanaan pekerjaan dapat berjalan dengan baik dan lancar.

Peralatan dan furniture yang dibahas antara lain:

\section{Meja}

Kelelahan kerja akan cepat terjadi dan timbul apabila kenyamanan dalam perabot meja dan kursi tidak memenuhi standar. Maka alangkah lebih baik apabila dalam pemilihan meja dan kursi kantor sesuai dengan fungsinya. Meja yang tingginya sesuai dengan rata-rata antropometri manusia. Misalnya sekitar $70 \mathrm{~cm}$, lebar meja pun juga menentukan produktivitas kerja seseorang, karena jika meja terlalu kecil ruang gerakpun terbatas dan membuat tidak nyaman, begitu juga sebaliknya jika terlalu luas pasti akan ada beberapa benda yang akan diluar jangkauan tangan. Ukuran yang pas sesuai kebutuhan akan lebih melegakan aktivitas, memberi kenyamanan dengan begitu pekerjaan menjadi produktif.

\section{2. $\underline{\text { Kursi }}$}

Kursi salah satu furniture yang sangat menentukan kenyaman dan keamanan aktivitas pekerja. Kursi yang aman harus mengikuti lekuk punggung dan sandaran dapat disesuaikan, 
memiliki tempat sandaran tangan juga disarankan, tetapi biasanya kursi model seperti ini hanya dipakai oleh seseorang yang memiliki jabatan di kantor atau perusahaanya. Jarang sekali ada kursi karyawan biasa yang ada sandaran tangannya. Ketinggian yang dapat disesuaikan juga menambah kenyamanan aktivitas pengguna. Sandaran kursi haruslah keras, tetapi berbantal empuk karena pekerja akan menghabiskan waktu untuk bekerja sekitar $8-10$ jam, terlebih juga pekerjaannya selalu didepan komputer. Selain itu, kursi yang baik haruslah memiliki lima kaki dan beroda sehingga tidak mudah jatuh dan memudahkah pergerakkan, disertai dengan kursi yang dapat diputar $360^{\circ}$.

\section{Komputer}

Komputer adalah salah satu alat yang sangat membantu memudahkan dalam proses bekerja dan hasilnya akan lebih baik apabila dibandingkan dengan mengerjakan manual.

\section{Air Conditioner (AC)}

Air Conditioner adalah alat yang menghubungkan pemanas dan ventilasi udara. Pada dasarnya alat ini memperkenalkan udara eksternal, kemudian membersihkannya, lalu menghangatkannya pada suhu yang diinginkan, serta menghasilkan kelembapan yang sesuai dengan keadaan manusia.

\section{Telepon}

Telepon merupakan alat untuk menerima dan menyampaikan informasi dengan cepat dan mudah.

\section{Mesin Fotocopy}

Alat untuk menyalin kembali document atau ilustrasi dengan menggunakan cahaya, panas, bahan kimia atau muatan listrik statis. Berdasarkan ukurannya, mesin ini bagi dalam 3 bagian yaitu:

- Mesin Fotocopy Kecil

- Mesin Fotocopy Sedang

- Mesin Fotocopy Besar

\section{Lemari Arsip}

Lemari yang biasanya berfungsi untuk menyimpan berbagai macam arsip, dan terdiri dari 1-2 pintu yang biasa terbuat dari kayu, besi, atau baja.

\section{Filling Cabinet}

Perabot kantor yang biasanya berbentuk segi empat memanjang yang berfungsi untuk menyimpan berkas - berkas atau arsip dan biasanya terdiri dari 2 - 6 laci. 


\section{Antropometri}

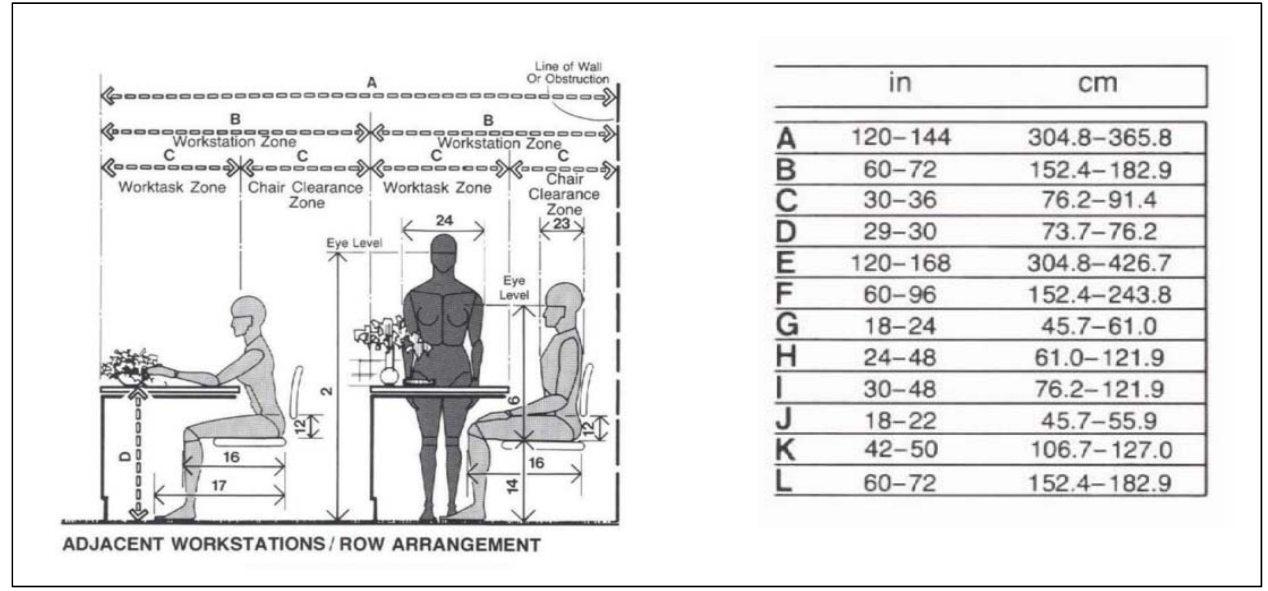

Gambar 13. Antropometri pos kerja yang berdekatan/ tata letak berbentuk baris Sumber: Human Dimension \& Interior Space (1979)

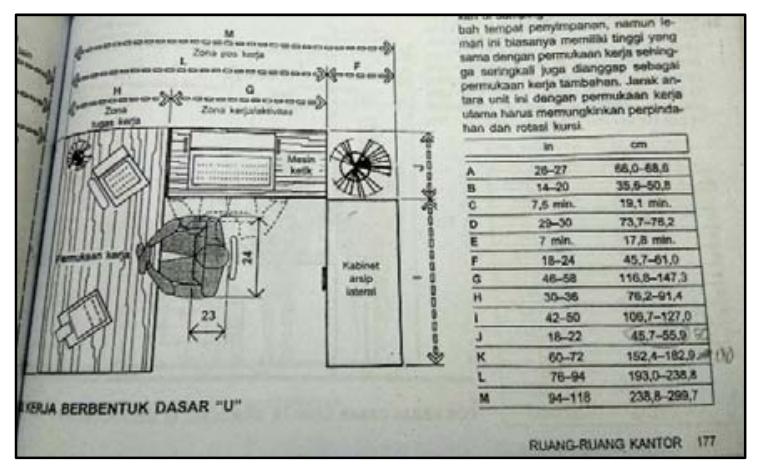

Gambar 14. Antropometri pos kerja berbentuk dasar "U" Sumber: Human Dimension \& Interior Space (1979)

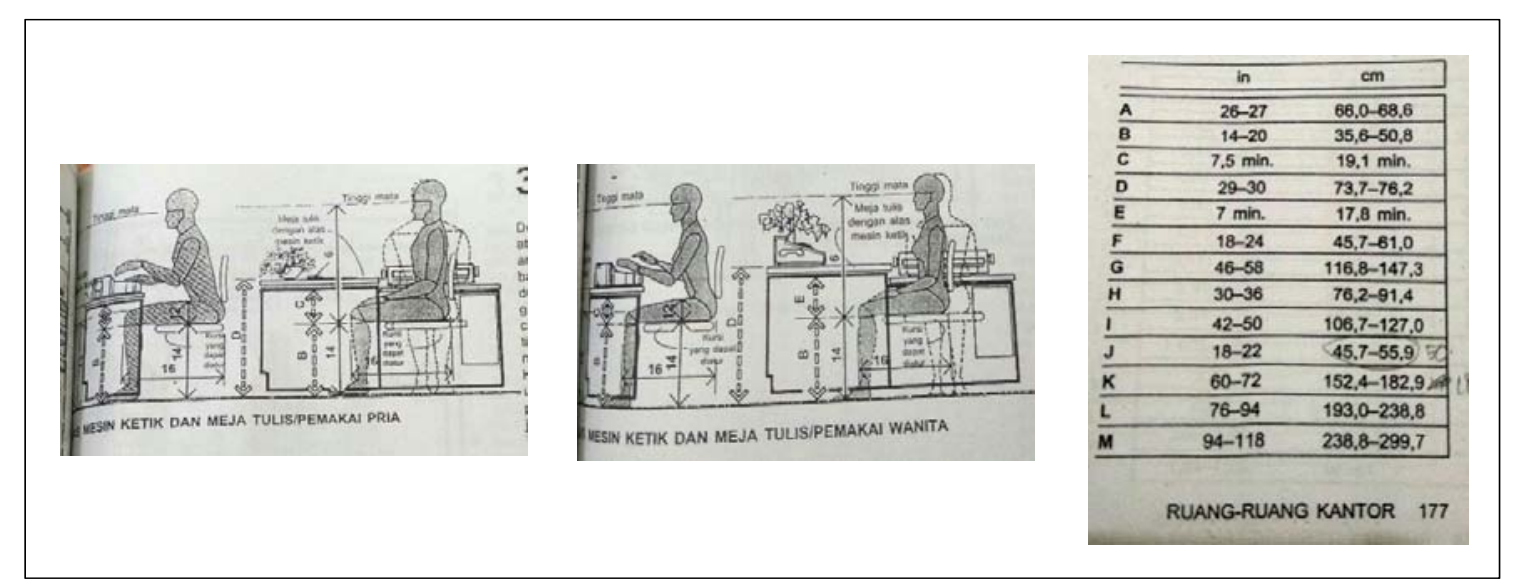

Gambar 15. Antropometri mesin ketik dan meja tulis Sumber: Human Dimension \& Interior Space (1979) 


\section{KESIMPULAN DAN SARAN}

Perancangan mebel untuk kantor Kezia Karin berikut bertujuan untuk meningkatkan produktivitas dengan pendekatan penyelesaian masalah dengan solusi desain sebagai berikut:

1. Menggunakan desain mebel yang sesuai dengan fungsi, cenderung ke multifungsi agar lebih hemat tempat dan ruang gerak.

2. Menerapkan desain berdasarkan standar kenyamanan menurut ergonomi agar ukuran mebel pas dengan ukuran pengguna.

Penerapan desain yang ergonomi akan sangat membantu dalam meningkatkan produktivitas pekerja karena pekerja akan merasa lebih nyaman dan aman. Mebel yang tidak menerapkan standar ergonomi akan mempengaruhi produktivitas pekerja serta kesehatan dalam jangka panjang.

\section{DAFTAR PUSTAKA}

Andre Halim dan IGN. Ardana. (2017). Perancangan Perabot Kerja Kantor untuk Menjembatani Gap Generation dan Mencegah Sick Building Syndrome. Jurnal Intra. Vol. 5 No. 2, 267-275.

Christianto Ciabrata A dan Adi Santosa, M Taufan Rizqy. (2017). Perancangan Furniture Fungsional Home Office Untuk Desainer Interior. Jurnal Intra. Vol. 5 No.2, 400-404.

Melisa Wiliaury, Adi Santosa dan Grace Setiati Kattu. (2015). Perancangan Mebel Multifungsi Untuk Dormitory Mahasiswa Desain. Jurnal Intra. Vol. 3 No. 2, 38-44.

Panero, Julius. (1979). Human Dimension and Interior Space; a Source Book of Design Reference Standard. New York: Whitney Library of Design.

Sedarmayanti. (2011). Manajemen Sumber Daya Manusia, Reformasi Birokrasi dan Manajemen Pegawai Negeri Sipil (cetakan kelima). Bandung: PT Refika Aditama.

Yuvensius Kevin Constantine dan Adi Santosa. (2015). Perancangan Mebel Multifungsi Untuk Home Office. Jurnal Intra. Vol. 3 No. 2, 162-166. 